\title{
Livros-vivos nas mãos de crianças brincantes: muitas histórias para contar
}

\author{
Eliane Santana Dias Debus* \\ Fernanda Gonçalves**
}

\begin{abstract}
Resumo
Este artigo centra-se no "Livro-vivo", aquele que por sua estrutura física se manifesta materialmente como vivo, ou seja, com espessura e textura do papel de maior resistência e durabilidade (cartonado), dobras movediças, imagens em alto relevo, entre outras artimanhas vinculadas a feitura do objeto, o que editorialmente no Brasil tem recebido o nome de livro brinquedo. Assim, busca-se evidenciar a composição do livro brinquedo e sua importância na formação do leitor, analisando o aspecto lúdico desse tipo de material e sua contribuição para a práxis educativa. Para isso, apresentamos a análise dos títulos Kokeshi, equipe Salamandra e Era uma vez..., de Benjamim Lacombe.

Palavras-chave: Livro brinquedo; Infância; Leitor.
\end{abstract}

\section{Living books in the hands of playful children: many stories to tell}

\begin{abstract}
This article focuses on the "Living Book", the one that by its physical structure manifests itself materially as alive, that is, with thickness and texture of the paper of greater strength and durability (paperboard), quick folds, embossed images, among others Tricks linked to the making of the object, which editorially in Brazil has received the name of toy book. Thus, it is tried to evidence the playful composition of the toy book and its importance in the formation of the reader; Seeking to exemplify the ludic aspect of this type of material and its contribution to the educational praxis, we present the analysis of the titles Kokeshi, Salamandra team and Era once ..., by Benjamim Lacombe.

Keywords: Book toy; Childhood; Reader.
\end{abstract}

Que os livros têm vida que nos levam a viver outras vidas, na relação personagem-leitor, talvez seja um fato já dado, pois já mereceu esforço intelectual de vários estudiosos para marcar essa posição (ECO, 2003; CANDIDO, 1995). No entanto, quando anunciamos neste artigo o olhar sobre o "Livro-vivo" nos reportamos aos livros que por sua estrutura física se manifestam materialmente como vivos, ou seja, com espessura e textura do papel de maior resistência e durabilidade (cartonado), dobras movediças, imagens em alto relevo, entre outras artimanhas vinculadas a feitura do objeto, o que temos denominado editorialmente no Brasil de livro brinquedo.

A expressão "Livro-vivo" foi cunhada pelo estudioso francês Jean Perrot (2002) ao pesquisar uma mostra significativa de livros europeus e norteamericanos que, por suas estruturas, "realçam e estimulam o gosto pela leitura, por prenderem o leitor ao prazer do mundo encantado das 'surpresas literárias"” (PERROT, 2002, p.34-35). Para o autor, a gratuidade aparente e a aproximação de sua confecção, e possível uso, com o brinquedo faz com que esse tipo de livro se distancie daqueles que se vinculam a atividades escolares, provocando uma *Endereço Eletrônico: elianedebus@ hotmail.com

***Endereço Eletrônico: feegoncalves@gmail.com "desdramatização do ato de ler" (PERROT, 2002, p. 36).

Embora o mercado editorial brasileiro tenha ampliado sua produção sobre esse tipo de acervo, cremos que as discussões teóricas e, em particular, a sua relação com as crianças pequenas com esses livros ainda se faz incipiente. Desse modo, este artigo busca evidenciar a composição do livro brinquedo e a sua importância na formação iniciática do leitor, analisando o aspecto lúdico desse tipo de material e sua contribuição para a práxis educativa. Para isso, apresentamos a análise dos títulos Kokeshi e Era uma vez..., de Benjamim Lacombe.

O critério de escolha dos dois exemplares está circunscrito na sua avaliação positiva e criteriosa pelos membros votantes da Fundação Nacional do Livro Infantil e Juvenil (FNLIJ), sendo vencedores do prêmio de Livro brinquedo respectivamente nos anos de 2013 e 2016. A instituição, reconhecida pelo seu trabalho de divulgação do livro infantil e juvenil, criou, em 1975, premiação destinada aos melhores livros para crianças do ano, o que ao longo dos anos foi se ampliando e hoje são dezoito categorias (Criança, 
Jovem, Imagem, Poesia, Informativo, Tradução Criança, Tradução Jovem, Tradução Informativo, Tradução Reconto, Projeto Editorial, Revelação Escritor, Revelação Ilustrador, Melhor Ilustração, Teatro, Livro Brinquedo, Teórico, Reconto e Literatura de Língua Portuguesa) (FNLIJ, 2014).

\section{Do ouvir ao contar: o objeto livro é presença}

Os exercícios de ouvir e contar histórias sempre estiveram presente nas nossas vidas, desde o momento do nosso nascimento aprendemos, a partir das experiências que vivenciamos e, também, por meio das experiências das quais os outros nos narram. Nós, seres humanos, sentimos desejo de contar fatos que vivenciamos, sentimos, pensamos, sonhamos. E é desse desejo que surgiu a literatura: "do desejo de ouvir e contar para, através desta prática, compartilhar" (KAERCHER, 2001, p.81).

Para formarmos crianças que gostem de ler e tenham uma relação de bem querer com a literatura é necessário que propiciemos experiências agradáveis, possibilidades de interação com o objeto livro e com o ato de ouvir e contar histórias desde muito cedo (KAERCHER, 2001). Nos primeiros anos de vida, as crianças estão conhecendo, explorando e descobrindo o mundo, e é justamente em contato com objetos da cultura humana que descobrem o novo.

A proximidade das crianças com os livros e com todo o universo cultural que as circunda deve acontecer desde muito cedo, quando ainda bebês. Os pequenos se interessam pelo mundo que os cerca, mostram-se curiosos e investigativos, desejosos de manusear o livro, de experimentá-lo e de senti-lo. Logo, a familiaridade, que as crianças estabelecem com os livros, proporcionará a elas experiências múltiplas: "possibilidades de imaginação e de criação de fantasias e compreensão da realidade. E, certamente, ele poderá gostar dos livros e da literatura" (PARREIRAS, 2012, p.21).

Partimos do pressuposto que toma a criança enquanto leitora desde pequenininha, uma vez que:

Ao cirandar pelas linhas e entrelinhas de livros tão cheios de colorido e vida, tão próximos das coisas prazerosas e gestos ternurizantes, por certo a criança pequena tecerá leituras e se constituirá leitor: Da leitura material do livro à leitura do texto. Do ser bebê ao ser leitor: Acreditamos que a inserção da criança no mundo lúdica da leitura literária desfaz algumas ideias preconcebidas, tais como a de que a criança pequena não é leitora. (DEBUS, 2006, p.43)

Deste modo, o contato da criança com o objeto livro pela feição material é considerado a primeira cerimônia de apropriação da leitura e levanos a refletir sobre as manifestações sensoriais que surgem pela interação palpável entre o leitor e o livro. Nessa perspectiva, poderíamos dizer que a leitura inicia-se pelos sentidos: a visão, o som, o toque. Ao tocar e sentir o livro, a criança vai ensaiando seu papel de leitor, experimentando a partir de uma leitura sensível que mexe com os prazeres do corpo:

Assim, a criança faz sua primeira leitura pelo contato com os elementos físicos constitutivos do livro: o tipo de papel, a textura, o volume, a extensão do número de páginas, o colorido das ilustrações etc. Esse esboço da leitura pode ocorrer já nos primeiros dias de vida do bebê, quando o aproximamos do livro objeto, isto é, dos livros de pano, de plástico e de outros materiais resistentes, como os de papelão, de borracha etc. Nesse momento, os livros com essas características ocupam um papel próximo ao do brinquedo: a criança tem a oportunidade de manter uma relação palpável com um objeto que se identifica com a estrutura física do livro. (DEBUS, 2006, p. 36)

Os muitos modos das crianças pequenas de se relacionar com esse objeto, ampliado pela relação corpórea, fica visível quando entre outros objetos do brincar ele também se torna brinquedo. O livro, muitas se vezes, é desconstruído de sua função aurática e vira uma pista para carrinhos, um travesseiro, um encostado, uma casinha, entre outras funções inusitadas que são vivificadas pela imaginação infantil. Por outro lado, a sua presença e as relações mediadas pelos adultos fazem com que os gestos iniciáticos de leitura se concretizem.

Assim, faz-se importante que as crianças percebam a leitura como uma ação contínua e, sobretudo, a sua função social. Deste modo, o livro precisa ser incluído no cotidiano, para que se sintam próximas e convidadas a manuseá-lo e descobri-lo em suas muitas possibilidades. A leitura pode iniciar pelas sensações provocadas ao ouvido, ao tato, ao olfato ou paladar, pois, antes de ser texto, o livro é um objeto com formas: "cor, textura, volume, cheiro ou barulho ao se folhear suas páginas" (AQUINO, 2012, p.45).

A experiência primeira das crianças, quando folheiam o livro, exploram com todos os seus sentidos, é importante para que tenham autonomia 
nas suas escolhas de textos e livros, mas, sobretudo, para que sintam que esse objeto é também pertencente a sua realidade social, que faz parte das experiências, memórias e infância.

Incluir os livros no cotidiano das crianças não se trata de uma alfabetização precoce, mas a inserção de uma prática sociocultural, que constitui subjetividades contemporâneas letradas e possibilidade criativa da vida (BARBOSA, 2014). Uma vez que formar uma atitude leitora antecede a técnica, o desafio que se coloca é, sobretudo, o de nos preocuparmos menos com o ensino das letras e mais com a construção de bases para que as crianças possam participar criticamente da cultura escrita e experimentar as diferentes possibilidades e modos de pensar escrito (BRITTO, 2012).

\section{Entre brincadeiras e leituras: o livro-brinquedo}

Ouvir e contar histórias (ficcionalizadas ou narrativas de vida) parecem ser práticas cotidianas nos espaços educativos para crianças pequenas, como algumas pesquisas têm demonstrado (AQUINO, 2012; JUNQUEIRA; GIROTTO, 2016; FURTADO, 2016), mas seria uma prática o contato efetivo das crianças com o objeto livro? As crianças têm acesso a livros que ampliem o seu repertório leitor e agucem a sua imaginação? Os livros brinquedos estão disponíveis para elas? São perguntas que merecem respostas, embora tenhamos a consciência da impossibilidade neste texto. Buscamos, ainda, pensar o quanto o mercado editorial tem promovido a ampliação desse acervo trazendo para o cenário das publicações o livrobrinquedo que colabora para uma leitura autônoma pelos pequenos.

Segundo Paiva (2013), o mercado editorial ativo se reformula com intuito de atender as demandas culturais e o livro-brinquedo é um suporte de leitura que tem chamado à atenção das crianças pequenas. Importante situar, que a denominação livro-brinquedo ainda é recente. No Brasil, esse termo começou a surgir nas chamadas das capas de livros infantis entre os anos de 2009 e 2010 (PAIVA, 2013). Os anos de 1980 marcaram o início da sua produção no país, ora com a intensificação das importações, ora com a produção própria, destaque aqui para os trabalhos com livros de panos de Isis e Valéria Gomes (Noquinha, Neneca Peteca e Auau Lambão) e da pesquisadora Lúcia Pimentel Góes que juntamente com sua filha Alice, apresentou pela editora Saxônia, os livros de madeira (Patota animalda e $O \mathrm{ir}$ ), ambos entre os anos de 1980 e 1990 (GOÉS, 1996).

O livro experimental ou livro interativo tornou-se em 1998 a categoria livro-brinquedo pela reconhecida Fundação Nacional do Livro Infantil e Juvenil (FNLIJ) ${ }^{1}$ Segundo Paiva (2013), sua produção e reconhecimento recentes justificam a falta de pesquisas e estudos mais profundos sobre sua importância. Seu estudo acerca da especificidade do livro-brinquedo na sua tese de doutoramento superou a imagem de superficialidade ou simples modismo editorial, que lhe era atribuído. Hoje, legitimado como categoria literária da FNLIJ, tem se distinguido das outras modalidades infantojuvenis que existem, justamente pelo seu grau de elaboração estratégica.

$\mathrm{O}$ grande diferencial desse artefato consiste no seu traço estético, que motivam as crianças convidando-as para leitura interativa, justamente pela sua característica brincante e sensorial:

O livro-brinquedo, suporte que se caracteriza pelo menos estrategicamente pelo divertimento acionado na expectativa materializada da obra que pula, dobra, escreve, apaga, gira, cheira, monta, desmonta, sobe, desce, estica, dimensiona, movimenta etc., provoca uma desmistificação do livro que fica na mão do professor na hora da leitura, ao convidar o leitor a uma apreciação manuseada, autônoma - que provocaria sentido -, afastada do distanciamento, da restrição, ora da reverência ao formal e de uma obrigatoriedade da leitura de seguimento linear. (PAIVA, 2013, p.31)

Importante salientar, que a maior parte do contato que as crianças pequenas têm com os livros são pelas mãos dos adultos, que os apresentam e contam as histórias, mas não promovem a interação direta das crianças. Foca-se no desempenho do adulto leitor como sujeito promotor da leitura, e no livro na sua dimensão literária, cenário este, sinalizado na pesquisa de Guimarães (2011).

O livro e as práticas de leitura precisam de mediação para que seja construída a noção do objeto livro como instrumento portador do conteúdo simbólico, sujeito a múltiplas interações e variadas significações (GUIMARÃES, 2011), mas, por vezes, ignora-se a dimensão exploratória necessária, por receio, pelo status que o objeto livro carrega, pelo alto investimento, pela escassez do acesso ou, às vezes, até mesmo por desinformação: o que se fazer de fato com o livro? O livro deve estar nas mãos das crianças, sobretudo, as bem pequenininhas? 
A experiência estética, lúdica e independente que o livro-brinquedo propicia às crianças mostra-se importante, uma vez que sua relação com o livro é motivada pela leitura sensível, que vai além da decodificação do código escrito, envolvendo uma exploração corporal, que comove e convida as crianças à exploração de ler brincando. Livros de pano, de borracha, livros que cantam, encantam, saltam, pulam e convidam: são esses os livros-brinquedo, que se propõem a ir além do formato usual, é livro que interage e quer ser brinquedo.

Sua proposta é justamente ser pensado de modo a proporcionar um contanto intenso, por vezes, até íntimo com as crianças. Livros que convidam ao toque por meio de diferentes texturas, nos pequenos detalhes das dobras, uma interação com as ilustrações. Entre segredos sobre dobras, entre canções que surgem ao simples aperto de uma tecla, entre personagens saltitantes em formato 3D, entre tramas, desejos e propostas surpreendentes, o que se coloca em cena não é a qualidade literária, mas a possibilidade de sentir-se profundamente imerso na experiência com o livro, é ler de outros modos, ler por possibilidades outras, leituras outras: profundas leituras.

Convite à brincadeira endossados a partir do próprio objeto: elementos brincantes que chamam as crianças, envolvem e permitem que esse objeto cultural componha efetivamente as suas brincadeiras. Brincadeiras que nos surpreendem, uma vez que os pequenos ultrapassam a proposta inicial do livro, recriam, reinventam, recontam as histórias, a partir das suas próprias culturas, das suas potencialidades criativas e inventivas.

A sua pretensão, é justamente:

[...] desde o início, em função objetivacomunicativa-expressiva, ser além do texto, ser suporte formado no desenvolvimento de recursos multimeios selecionados e aperfeiçoados à arte-criação. Possivelmente porque mexe com inclinações infantis, impulsos/pulsões, afetos, sentimentos, prazer sensorial, vontades primárias (ver, olhar, tocar, sentir), acolhe e ressoa anseios em projeções de entusiasmo enlaçador. Belo e surpreendente, torna-se desejado na dimensão do brinquedo, porque a criança não precisa reconhecê-lo nem pela dimensão de mercadoria nem pela da arte, muito menos por seu valor expresso educativo. A criança aprende pelo brincar, porque se afeiçoa, se diverte e deslumbra maravilhas lúdicas, orientando a experiência não ao contemplativo mediado, mas ao aprender usando. (PAIVA; CARVALHO 2011, p.32)

A partir de algumas experiências em oficinas de leitura e criação no contexto da Educação Infantil, Paiva e Carvalho (2011) argumentam que o livro-brinquedo incita as crianças a uma participação intensa na interação com o objeto livro, a uma socialização e partilha de acontecimentos. Ele convida a querer experienciá-lo pelos seus aspectos instigantes: morder, cheirar, pegar, apertar, balançar, rodar, ouvir, dentre outros.

Para Corsino e Mattos (2012), o livrobrinquedo tem se mostrado como suporte de leitura ideal para as crianças bem pequenas, na faixa etária de zero a três anos, principalmente pela sua materialidade ser mais resistente em alguns casos. O objetivo principal seria, para as pesquisadoras, introduzir os gestos de leitura, como folhear as páginas, identificar e nomear elementos, mas, sobretudo, é uma aposta na autonomia da criança no manuseio que estabelecem nas interações e leituras. Contudo, uma pequena parcela desta categoria de livro alia as características interativas e brincantes às narrativas de histórias, sendo que, a maioria não apresenta um tratamento literário à linguagem, focando mais os aspectos materiais e menos os textuais.

Dos livros escolhidos para análise Kokeshis e Era uma vez, veremos que o primeiro, embora se caracterize como livro brinquedo pela sua materialidade, apresenta um texto literário, no caso do segundo os aspectos estéticos ficam vinculados à estrutura.

\section{O livro Kokeshis e suas possibilidades de interação}

O livro-brinquedo é composto por uma caixinha com formato Kokeshi ${ }^{2}$, e dentro dele encontramos: um livro em formato de Kokeshi com um conto japonês (o livro com a história); uma pequena pasta em forma de Kokeshi com folhas para fazer origamis com a explicação de modelos; um caderno para aprender a desenhar Kokeshis, uma bonequinha Kokeshis e adesivos que dialogam com a história.

O conto japonês, que encontramos dentro do livro-brinquedo Kokeshi, chama-se $O$ segredo de Mitsuko (Figura 1) -recontado por Brigitte Delpech e ilustrado por Demunynck -, narra a história de uma jovem que morava no Reino do Norte, além das montanhas junto com seu avô. De coração leve, costumava cantarolar o dia inteiro, conquistando o 
carinho de todos. Mitsuko era a responsável em bordar os quimonos de seda de todas as jovens que se casavam em sua aldeia, ela também sabia dobrar folhas de papel para fazer pássaros coloridos, conhecidos como Tsuru.

FIGURA 1: O Livro-brinquedo Kokeshis

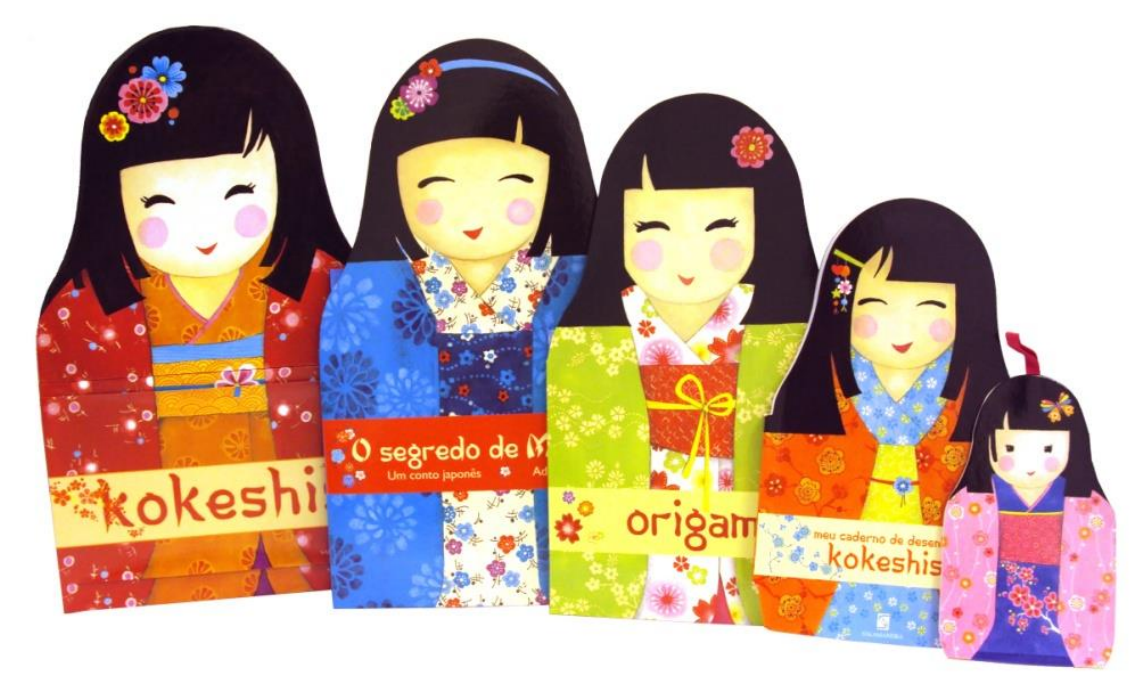

Fonte: Editora Salamandra

Os elementos que encontramos no conto são também as propostas de brincadeiras junto ao livrobrinquedo, que acompanha papéis para a construção de origami com explicações dos processos da dobradura do Tsuru, assim como a personagem Mitsuko fazia no conto.

Kokeshis apresenta-se como uma proposta de livro-brinquedo para as crianças maiores, que gostam de narrativas mais estruturadas e, ainda sim, podem brincar e interagir com as possibilidades que acompanham o conto: como fazer origamis, desenhos de Kokeshis. Esta nova forma de sentir o livro, convidativa, interativa e exploratória, vem atraindo a atenção das crianças, principalmente pelo seu formato distinto e características ornamentais. Sabe-se que o livro-brinquedo pode ser um poderoso aliado, incentivando as crianças à brincadeira, logo, a leitura prazerosa.

Para as crianças bem pequenininhas o que mais chama atenção são outras possibilidades interativas: como a exploração dos sentidos por meio das cores e texturas, por exemplo, ou livros com uma materialidade resistente, já que a interação corporal é intensa. Isso não significa dizer que as crianças bem pequenas não se interessam por contação de histórias, mas com a especificidade da faixa etária das crianças de 0 a 3 anos, é necessário um planejamento intencional dos professores para esses momentos.
O grande diferencial desse livro-brinquedo é que nos apresenta uma nova proposta de leitura, que envolve a ludicidade com uma narrativa, com belíssimas ilustrações que dialogam com o conto. Outro elemento que pode propiciar a brincadeira é o próprio tema abordado nos livros de literatura infantil, ou gêneros, como: mitos, lendas, jogos, contos de fada, fábulas, trava línguas, entre outros. Mas o livro-brinquedo é uma categoria de livro que proporciona uma relação interativa e experiências sensoriais, justamente pela sua materialidade.

\section{Era uma vez... tantas vezes que não soube contar}

Os contos de fadas por certo mexem com o imaginário coletivo de todas as idades. Qual adulto frente a uma imagem de uma campanha publicitária que remonte a uma modelo de capa vermelha na floresta imediatamente não se lembre da personagem Chapeuzinho Vermelho? Esse pequeno exemplo poderia se ampliar sucessivamente, pois muitas são as personagens feéricas que povoaram e povoam a infância das crianças que fomos e daquelas que serão.

Provavelmente, motivado pelo domínio público dessas narrativas, o mercado editorial investe desmesuradamente nesse filão trazendo, muitas vezes, publicações sem qualidade ética e estética. No primeiro caso, são adaptações que não 
indicam a origem e autoria do texto, inseridas em coleções que, desbragadamente indexam erroneamente gêneros literários (lenda, fábulas, conto de fadas) como se fossem idênticos. No segundo caso, ilustrações de pouca qualidade adquiridas em bancos de imagem, tipo de papel, tamanho de letras indevido, entre outros.

No caso dos livros brinquedos, a presença dos contos de fadas também se faz constante. Destaca-se entre essas publicações

FIGURA 2: Era uma vez

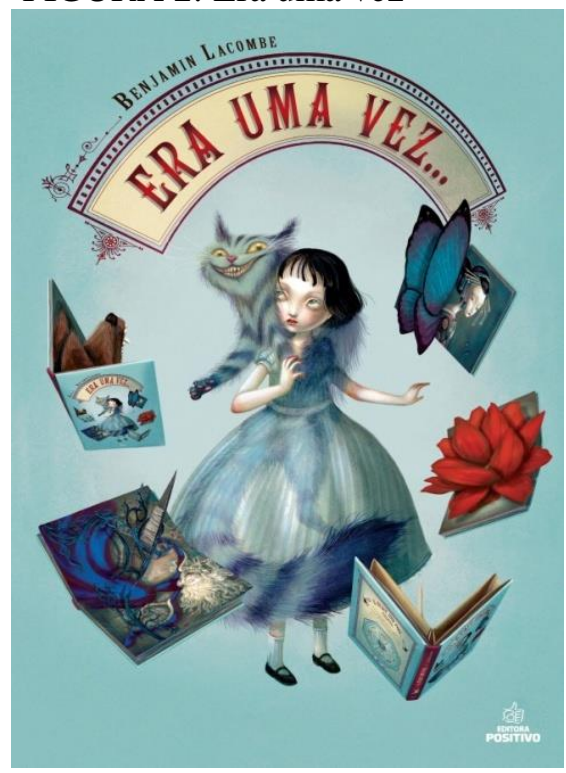

Fonte: editora Positivo

As pétalas da flor, em seu vermelho rubro, se desdobram pela página e agasalham a pequena Polegarzinha, de olhar inquieto; Pinóquio, sob a moldura dobrável do palco, apresenta-se na boca de cena do circo; na bocarra do lobo que se abre sobre a página, a menina Chapeuzinho Vermelho desaparece. Entre cartas suspensas, como que enlaçadas por pequenos fios, Alice vive seu sortilégio num País que não é tão maravilhoso. Sob um tenebroso cenário, o leitor pode espiar pelas fendas no papel o suplício de uma das esposas do Barba Azul, que a tudo espreita. Na representação do fuso, envolto de vegetações insólitas que se pronunciam no centro da página, adormecida esta A Bela Adormecida e, na presença do olhar terno da lua arredondada e do Big Ben, Peter Pan leva as crianças Darling para a Terra do Nunca. Talvez Madame Butterfly se distancie das narrativas feéricas, mas por certo, Lacombe a introduziu com perfeição na sua insólita construção que desfilam pelas páginas em dobraduras em três dimensões.

$\mathrm{O}$ entrelaçamento da composição das contemporaneíssimas o livro Era uma vez... (Figuras 2 e 3), ilustrado por Benjamin Lacombe com arquitetura de papel de José Pons que veio a público na França em 2010 e no Brasil em 2015. Publicação arrojada de um livro que é arte pura, magistralmente sedutor pela sua arquitetura física e imagens insólitas. Um livro pop-up, composto sem palavras e carregado de imagens dos personagens clássicos dos contos para infância.

FIGURA 3: A polegarzinha

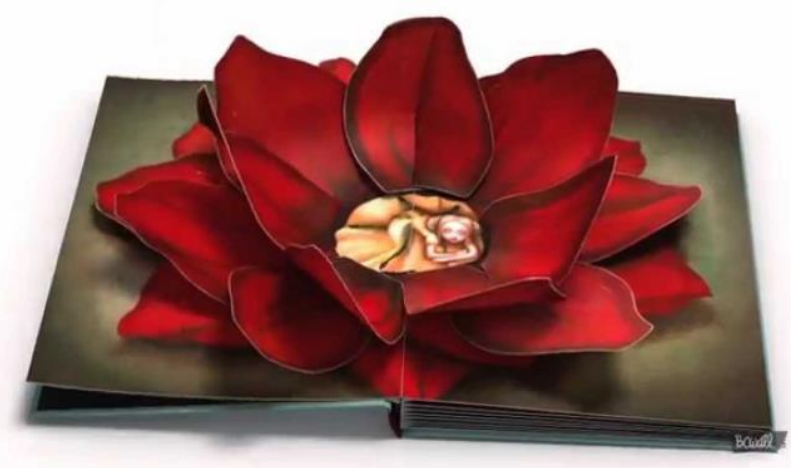

Fonte: editora Positivo

imagens das personagens dos contos de fadas (Chapeuzinho Vermelho, Polegarzinha, Barba Azul) e a dos contos modernos (Peter Pan, Pinóquio e Alice) são ampliadas pela arquitetura do papel que se dobra, desdobra e se torna cenário para as suas peripécias aventurescas.

O posfácio de Jean Perrot, estudioso desse tipo de livro, "Era uma vez... um livro surrealista", capacita o leitor a entrar nas mesuras da construção do livro naquilo que se faz mais pulsantes, exemplificando os detalhes dos recursos tipográficos, as minúcias dos elementos das ações de algumas das narrativas; os detalhes e interações das cores entre as páginas.

Era uma vez... é um livro carregado de pequenos detalhes que provoca a curiosidade $\mathrm{e}$ mantém o olhar atento do leitor preso as suas dobras. No entanto, o artefato inusitado guarda fragilidades que, por certo, não se insinuam a primeira vista, mas se torna impossível ao virar as páginas não pensar sobre a sua durabilidade nas mãos dos pequeninhos. 
Vale também destacar que esse tipo de artefato cultural, artisticamente bem construído, reúne elementos que contribuem para a apreciação estética do objeto livro não se restringindo ao público infantil especificamente, mas a todos aqueles que se interessam pelos meandros da sua confecção.

\section{Das (In)conclusões: porque ficam tantas histórias em aberto}

É importante que as crianças possam sentir e experenciar o livro na sua inteireza. Para tanto, é imprescindível ponderarmos acerca da especificidade dos livros que são propostos a elas, para que possam explorar o objeto livro sem serem coibidos. O livro-brinquedo tem como propósito propiciar as ações lúdicas das crianças para que, elas mesmas, encontrem seus modos próprios de leituras e exploração.

Outro elemento importante é que o livrobrinquedo, "enquanto suporte editorial para a infância, pode ser uma representação de publicação literária, com histórias, narrações, tramas, enredos, ou ser apenas um brinquedo" (PAIVA; CARVALHO, 2011, p.34). Ou seja, pode ser um suporte para ampliar as brincadeiras, para o convite à cerimônia sensorial de leitura, ou, pode ser aquele que convida à brincadeira, mas alinha-se a qualidade literária do texto.

É relevante chamar a atenção para importância de pensarmos em espaços e tempos que promovam a interação das crianças com os mais distintos livros, espaços estes que estejam preocupados em possibilitar a autonomia das crianças, respeitando suas escolhas, seus tempos, suas brincadeiras.

A exploração do livro-brinquedo pode propiciar a atividade lúdica, a imaginação, a descoberta, a exploração, a ampliação do repertório cultural e, sobretudo, uma profunda proximidade a esse artefato cultural, portador das mais distintas histórias e subjetivações. É importante que as crianças tenham suas relações com os livros permeadas pela intimidade, por possibilidades prazerosas - ou não - mas que sejam autônomas, sem que sejam restringidas, impedidas de estar com os livros, que eles componham suas brincadeiras e suas vidas.

No caso dos dois livros Kokeshis e Era uma $v e z$ constata-se a ludicidade em sua estrutura e o primor gráfico com que foram confeccionados, demonstrando a possibilidade de inserção desse tipo de livro no mercado editorial. Cabendo agora aos mediadores pensar com inseri-los nos espaços educativos. Mas isso já é outra história.

\section{Notas}

1 A FNLJ tem como objetivo: "Valorizar a leitura e o livro de qualidade; - Divulgar a produção brasileira de livros de qualidade para crianças e jovens e, em particular, os livros de literatura e informativos; - Contribuir para a formação leitora dos educadores, sejam professores, bibliotecários ou pais, quanto ao conhecimento das teorias e experiências sobre temas afins, tais como leitura, literatura e formação de bibliotecas; - Promover a tolerância, a solidariedade e a paz por meio da leitura partilhada; - Valorizar a biblioteca da escola e a pública como o lócus para o processo democrático à cultura escrita e mantenedora da prática da leitura". Informações disponibilizadas em: $\quad$ http://www.fnlij.org.br/site/o-que-e-afnlij.html. Acesso em 06 de maio de 2014.

2 Kokeshi são bonecas japonesas de madeira. Normalmente, pintadas com linhas finas que demarcam o rosto, no corpo possuem desenhos florais.

\section{Referências}

AQUINO, Kenia Adriana de. O nascimento do leitor: ler, contar e ouvir histórias na educação infantil. 1 ed. Boa Esperança, MT: EduFMT, 2012.

BARBOSA, Maria Carmen S. A leitura na creche: qual leitura? In: FARIA, Ana Lúcia Goulart de.; VITA, Anastasia de Vita (Orgs.) Ler com bebês: contribuições das pesquisas de Susanna Mantovani. Campinas, SP: Autores Associais, 2014, p.VIII-XII.

BRITTO, Luiz Percival Leme. Letramento e Alfabetização: implicações para a educação infantil. In: FARIA, Ana Lúcia Goulart de; MELLO, Suely Amaral. (Orgs.). O mundo da escrita no universo da pequena infância. São Paulo: Autores Associados, 2012. p. 3-19.

CANDIDO, Antonio. O direito à literatura. Vários escritos. 3 ed. São Paulo: Duas Cidades, 1995.

CORSINO, Patrícia; MATTOS, Maria Nazareth de S. Salutto De. As crianças pequenas e os livros no 
cotidiano de uma creche comunitária da cidade do Rio de Janeiro. In: XVI ENDIPE - Encontro Nacional de Didática e Práticas de Ensino. Anais UNICAMP. Campinas, 2012.

DEBUS, Eliane. Festaria de brincança: a leitura literária na educação infantil. 1 edSão Paulo: Paulus, 2006.

DELPECH, Brigitte. O segredo de Mitsuko. Trad. Equipe Salamandra. In: Kokeshis. Editora Salamandra, São Paulo, 2011. http://www.fnlij.org.br/site/premio-fnlij.html. Acesso em 06 de maio de 2014.

ECO, Umberto. Sobre a literatura. Trad. Eliana Aguiar. 2 ed. Rio de Janeiro: Record, 2003.

FURTADO, Thamirys Frigo. Espaços e tempos coletivos de leitura literária na Educação Infantil da Rede Municipal de Florianópolis (SC). 2016. 151 p. Dissertação de Mestrado, Universidade Federal de Santa Catarina (UFSC), 2016.

GOÉS, Lúcia Pimentel. Olhar de descoberta. Il..Eva Furnari. 1 ed. São Paulo: Mercuryo, 1996.

GUIMARÃES, Rosele Martins. Encontros, cantigas, brincadeiras, leituras: Um estudo acerca das interações dos bebês, as crianças bem pequenas com o objeto livro numa turma de berçário. 2011. 259 p. Dissertação de Mestrado - Universidade
Federal do Rio Grande do Sul, 2011.

KAERCHER, Gládis E.. E por falar em literatura... In: CRAIDY, Maria e KAERCHER, Gládis E.(Orgs.). Educação Infantil: pra que te quero. Porto Alegre: Artmed Editora, 2001. p.81-88.

LACOMBE, Benjamin. Era uma vez...Trad. Lavinia Fávero. Curitiba: Positivo, 2015.

PAIVA, Ana Paula. Um livro pode ser tudo e nada: especificidades da Linguagem do livro-brinquedo. 2013. 736 p.Tese de Doutorado- Universidade Federal de Minas Gerais, Belo Horizonte, 2013.

PAIVA, Ana Paula; CARVALHO, Amanda Carla Minca. Livro-brinquedo, muito prazer. In: Inserir autores. Leitura literária na escola: reflexões e propostas na perspectiva do letramento. Mercado das Letras, São Paulo, 2011, p. 13-47.

PARREIRAS, Ninfa. Do ventre ao colo, do som à leitura: livros para bebês e crianças. 1 ed. Belo Horizonte: RHJ, 2012.

PERROT, Jean. Os livros-vivos franceses. Um novo paraíso cultural para nossos amiguinhos os leitores infantis. In: KISHIMOTO, Tizuko M. 2. ed. $O$ brincar e suas teorias. São Paulo: Pioneira, 2002, p.33-53.

\section{Sobre as autoras}

Eliane Santana Dias Debus possui graduação em Letras Licenciatura Português e Inglês pela Fundação Educacional de Criciúma (1991), mestrado em Literatura pela Universidade Federal de Santa Catarina (1996) e doutorado em Linguística e Letras pela Pontifícia Universidade Católica do Rio Grande do Sul (2001). Atualmente é professora da Universidade Federal de Santa Catarina, atuando no Departamento de Metodologia de Ensino e no Programa de Pós-Graduação em educação. É líder do Grupo de Pesquisas LITERALISE: Grupo de pesquisa em literatura Infantil e juvenil e práticas de mediação literária, da Universidade Federal de Santa Catarina.

Fernanda Gonçalves é Doutoranda no Programa de Pós-Graduação em Educação da Universidade Federal de Santa Catarina, linha de pesquisa Sujeitos, Processos Educativos e Docência (SUPED). É Mestre em Educação pela mesma universidade, na linha de pesquisa Educação e Infância (2014). É Graduada em Pedagogia com habilitação em Educação Infantil e Séries Iniciais também pela Universidade Federal de Santa Catarina (2012). É integrante do Grupo de Pesquisa em Literatura Infantil e Juvenil e Práticas de Mediação Literária (LITERALISE).

Submetido em maio de 2017.

Aprovado em setembro de 2017. 